\title{
AOR
}

Selected Papers of \#AolR2019:

The $20^{\text {th }}$ Annual Conference of the Association of Internet Researchers Brisbane, Australia / 2-5 October 2019

\section{EXAMINING THE "ELSAGATE" PHENOMENON: DISTURBING CHILDREN'S YOUTUBE CONTENT AND NEW FRONTIERS IN CHILDREN'S CULTURE}

Jessica Balanzategui

Swinburne University of Technology

Contemporary children are turning to online video streaming as an "alternative for TV" (Ha 2018,1 ) in increasing numbers (see Australian Communications and Media Authority 2017, 20-22). In addition, US-based global video streaming platforms, primarily YouTube and Netflix, are becoming "more influential in screen production ecologies" when it comes to children's content (Potter 2017a, 22). Yet, as increasing numbers of children consume much of their video content outside of the legacy media spaces of film and television, serious concerns are being raised in policy, advocacy (Centre for Digital Democracy, 2018), and journalistic (Bridle, 2017) discussions around the globe because many new children's video streaming genres are not "child-appropriate" according to extant definitions and guidelines, such as the internationally endorsed Children's Television Charter.

Alarms have been raised in relation to new genres on YouTube in particular. For instance, in an influential journalistic exposé, James Bridle (2017) argues that YouTube content seemingly aimed at child-viewers is tantamount to "a kind of infrastructural violence" against children's wellbeing, a point echoed in many other recent long-form journalistic investigations (see for instance Orphanides 2018). Public concerns about the strange approach to children's content exhibited by various YouTube genres have become so prevalent that the neologism "Elsagate" is now commonly used in media reportage to describe the scandal. The term references the Disney character "Elsa" from the popular animated children's film Frozen (2013), who often features in unnerving, child-oriented YouTube content, represented through either low quality digital animation or in liveaction via adult performers wearing cheap "Elsa" costumes. In such content, Elsa is depicted alongside other popular characters from different family media franchises: in particular, Spider-Man and Elsa often appear as a romantic couple. The content depicts such characters interacting in mundane but often comedic or surreal domestic scenarios, engaging in romantic relationships, violently assaulting each other, and/or performing Suggested Citation (APA): Balanzategui, Jessica. (2019, October 2-5). Examining the "ElsaGate" Phenomenon: Disturbing Children's YouTube Content and New Frontiers in Children's Culture". Paper presented at AolR 2019: The $20^{\text {th }}$ Annual Conference of the Association of Internet Researchers. Brisbane, Australia: AolR. Retrieved from http://spir.aoir.org. 
various bodily functions. As Jean Burgess (2018) recently suggested in a keynote presentation for the Australian Academy of the Humanities, "commercial children's media is converging with the platform logics of the 'ambivalent internet"', which has driven a moral panic about whether or not parents can trust video streaming platforms to deliver children's content.

This paper aims to articulate why particular YouTube genres raise potent cultural anxieties about the role of YouTube in children's culture, and the effects and child appropriateness of YouTube content. The paper contends that the child-oriented YouTube genres at the centre of the Elsagate controversy re-position extant cultural boundaries of childappropriate content - boundaries which in some cases have long been enshrined in policy and standards guidelines - in ways that trouble culturally ingrained ideological distinctions between child and adult culture.

Deploying theoretical frameworks drawn from childhood studies, I argue that the concerns that dominate the "Elsagate" phenomenon - including the role of algorithms in distributing and producing children's content (Bridle, 2017), and the presence of adult performers playing perverse versions of familiar children's characters in "character mash-up" videos (Weiss, 2017) - circulate around a dissolution of the carefully calibrated "public value" (Potter, 2015) framework that has long underpinned industry and policy approaches to children's content in numerous countries. The analysis reveals that across the reportage on the Elsagate phenomenon, anxieties constellate around the opaque motivations and intentions behind the production of these new children's genres (Brandom, 2017). Furthermore, reportage consistently dwells on parents' and adult commentators' belated awareness of these unfamiliar, "bizarre" (Popper, 2017) genres popular with children, and suggests that children value this content for reasons that are unclear to adult guardians. Thus, "disturbing" (Sudebar and Yate, 2017) children's YouTube content interrupts traditional power balances and interplays between children's media industries, parental mediation strategies, and "child-effects": young children's agency over their own consumption choices and influence on parental media practices (Bulck et al, 2016).

The research presented has two components. The first component combines discourse and thematic analysis of journalistic investigations into inappropriate children's content on YouTube in order to identify the genres that have provoked the most public concern, and to illuminate the key anxieties that consistently underpin reportage about disturbing new children's genres. This research also traces the origins and development of the Elsagate phenomenon through a comprehensive collation of reportage about disturbing children's YouTube content.

The second component features a genre studies textual analysis of the YouTube content itself in order to identify the recurring narrative structures, tropes, and aesthetics that shape these new children's genres. This component deploys Rick Altman's semantics/syntactics approach to genre analysis, which is a valuable tool for the identification of new genres because it aims to identify textual patterns. The semantics, or "building blocks" of genre $(1984,10)$, include character types, aesthetic traits, iconography, and settings. The syntactics, or "meaning-bearing structures" (Altman, 11) of a genre, are the "constitutive relationships" (10) into which a genre's semantics are arranged. The content analyzed includes videos and genres mentioned repeatedly across the Elsagate reportage, with 
between thirty and fifty videos analyzed in each genre category (such as "character mash-up" videos) in order to identify common thematic, structural, and aesthetic patterns.

The paper will illustrate how children's genres on YouTube that have been deemed disturbing or bizarre in journalistic commentary align with and deviate from children's genres in public and commercial children's media. In addition, the paper will highlight how these genres introduce new iconography, themes, and narratives into the terrain of children's culture which challenge longstanding demarcations between children's and adult's culture. The paper will show that this rapid shift in children's cultural forms - a shift orchestrated not by the institutional mechanics of public and commercial children's media industries, but by children's own consumption patterns and navigation of algorithmic content recommendation trends - in part fuels the moral panic surrounding the Elsagate phenomenon.

\section{References}

Altman, R. 1984. "A Semantic/Syntactic Approach to Film Genre." Cinema Journal, 23 (3), p. 6-18.

Australian Communications and Media Authority. 2017. "Children's Television and MultiScreen Behaviour." Canberra.

Australian Government: Department of Communications and the Arts. 2017. "Australian and Children's Screen Content Review Consultation Paper." Canberra.

Brandom, Russell. 2017. "Inside Elsagate, the conspiracy-fueled war on creepy YouTube kids videos." The Verge.

Bridle, J. 2018. "How Peppa Pig became a video nightmare for children." The Guardian.

Bridle, J. 2017. "Something is wrong on the internet." Medium.

Bulck, J Van den, Custers, K \& Nelissen, S. 2016. "The child-effect in the new media environment: challenges and opportunities for communication research." Journal of Children and Media 10(2), p. 30-38.

Burgess, J. 2018. "What fake Peppa Pig videos can teach us about trust." Keynote: Trust and its Discontents Workshop, Australian Academy of the Humanities, Melbourne, September 28.

Centre for Digital Democracy et al. 2018. "Request to Investigate Google's YouTube Online Services and Advertising Practices for Violating the Children's Online Privacy Protection Act." Complaint filed to Federal Trade Commission. Washington.

Ha, L. 2018. "YouTube as a Global Online Video Portal and an Alternative to TV" In Ha, $\mathrm{L}$ (ed). The Audience and Business of YouTube. Lanham: Lexington Books. p, 116. 
Orphanides, K.G. 2018. "Children's YouTube is still churning out blood, suicide and cannibalism." Wired.

Popper, B. 2017. "YouTube says it will crack down on bizarre videos targeting children." The Verge.

Potter, A. 2017a. "Regulating contemporary children's television: how digitisation is reshaping compliance norms and production practices." Media International Australia 163(1), p, 20-30.

Potter, A. 2015. Creativity, Culture and Commerce: Producing Australian Children's Television with Public Value. Bristol: Intellect.

Sudebar, A \& Yates, W. 2017. "The disturbing YouTube videos that are tricking children." BBCNews.

Weiss, G. 2017. "YouTube's latest bizarre trend has adults dressing up in Spider-Man and Elsa Costumes." TubeFilter. 